\title{
Treatment of diesel-polluted clay soil employing combined biostimulation in microcosms
}

\author{
G. A. Silva-Castro $\cdot$ L. SantaCruz-Calvo • \\ I. Uad $\cdot$ C. Perucha $\cdot$ J. Laguna $\cdot$ J. Gónzalez-López $\cdot$ \\ C. Calvo
}

Received: 6 April 2011/Revised: 2 August 2011/Accepted: 8 December 2011/Published online: 12 April 2012

(c) CEERS, IAU 2012

\begin{abstract}
The efficiency of inorganic fertilizers as stimulating agents for the bioremediation of oil-polluted environments can be increased with the addition of selected biostimulating compounds. In this study, the efficacy of different biostimulation treatments in the remediation of diesel-polluted soil in purpose-built microcosms has been evaluated. The treatments involved combinations of inorganic fertilizer with (a) Ivey surfactant, (b) Biorem organic fertilizer and (c) ethanol. Microbial activity was evaluated by monitoring the growth of heterotrophic and degrading bacteria and their dehydrogenase activity and carbon dioxide production. Hydrocarbon degradation was monitored by gas chromatography/mass spectrometry. The results showed that all treatments enhanced microbial activity in comparison with natural attenuation and also that the combined treatments generally enhanced hydrocarbon biodegradation in comparison to both natural attenuation and the single inorganic fertilizer treatment. The inorganic fertilizer plus Ivey ${ }^{\circledR}$ surfactant was the most efficient treatment in terms of Total Petroleum Hydrocarbon and light and heavy $n$-alkanes, showing an index of degradation of 1.4 and 1.3, respectively. Furthermore, biodegradation of heavy and branched $n$-alkanes was higher in microcosms treated with inorganic fertilizer plus ethanol (Index of degradation values of 1.6 and 1.5,
\end{abstract}

G. A. Silva-Castro - L. SantaCruz-Calvo - I. Uad .

J. Gónzalez-López · C. Calvo ( $\square)$

Department of Microbiology, Institute of Water Research,

University of Granada, 18071 Granada, Spain

e-mail: ccalvo@ugr.es

C. Perucha $\cdot$ J. Laguna

AG Ambiental, C/Isla del Hierro $71^{\text {a }}$ Planta, San Sebastián de lo Reyes, 28700 Madrid, Spain respectively) indicating that combined treatments can be very effective in restoration of contaminated soil.

Keywords Bioremediation - Hydrocarbon pollution ·

Surfactant

\section{Introduction}

Bioremediation offers a more environmentally friendly alternative to the degradation of oil by taking advantage of oil-degrading microorganisms and by establishing and maintaining the physical, chemical and biological conditions that favour enhanced oil biodegradation rates in the polluted environment (Kanaly and Harayama 2000; Bento et al. 2005; Sarkar et al. 2005). Biological processes have been successfully used to remediate soils polluted with petroleum hydrocarbons and their derivatives (Gan et al. 2009; Cunnighan and Philp 2000).

The biostimulating process introduces additional nutrients into a polluted system to increase the numbers of indigenous microorganisms. Contamination of a zone with hydrocarbons leads to a rapid depletion of the available pools of major inorganic nutrients, such as $\mathrm{N}$ and $\mathrm{P}$. Consequently, nutrient supplementation for hydrocarbon degradation has traditionally focused on the addition of nitrogen and phosphorus, either in the organic or inorganic forms (Sarkar et al. 2005; Bento et al. 2005; EPA 2001).

Besides adding nutrients to accelerate the breakdown of oil by microorganisms, another approach that enhances oil biodegradation involves increasing oil dispersion by the addition of either chemical or biological surfactants (Franzetti et al. 2008; Calvo et al. 2009). In general, microbial attack takes place at the oil-water interface, and thus enhanced biodegradation should result as a 
consequence of the increased surface area available for microbial colonization (Nikolopoulou and Kalogerakis 2008; Mulligan et al. 2001; Banat et al. 2000).

Emulsifiers can emulsify hydrocarbons by enhancing their water solubility and increasing the displacement of oily substances from soil particles. For these reasons, the inclusion of surfactants in the bioremediation treatment of a hydrocarbon-polluted environment could be beneficial. Thus, the addition of surfactants and other natural emulsifying agents is an important tool for the biotreatment of hydrocarbon-polluted environments (Calvo et al. 2009; Ron and Rosenberg 2002).

In order to demonstrate the viability of bioremediation of an oil-polluted soil, it is necessary to check the rate of hydrocarbon biodegradation under controlled conditions. Laboratory feasibility studies involve microbiological and chemical methods to measure the effectiveness of bioremediation under predetermined conditions. In general, soil microcosm experiments are useful tools for assessing the biodegradation potential of hydrocarbon contamination (Sabaté et al. 2004).

In this study, experiments to assess changes in both microbial activity and hydrocarbon composition during diesel bioremediation treatments were carried out at the laboratory scale using soil microcosms. The aim of this research was to determine the extent of oil hydrocarbon degradation under different experimental conditions in which inorganic fertilizer (NPK) was combined with various useful biostimulating agents like Ivey surfactant ${ }^{\circledR}$, Biorem organic fertilizer and ethanol.

This research was carried out in the laboratory of Environmental Microbiology during 2010.

\section{Materials and methods}

\section{Soil samples}

A clay soil sample polluted at the laboratory by adding $20,000 \mathrm{mg} / \mathrm{kg}$ of diesel was used in this study. The chemical and physical characteristics of the clay soil were determined according to Bremner and Blackmer (1982); Olsen and Sommers (1982), and the Soil Conservation Service, Soil Taxonomy (1975). Characteristics of soil were clay $77 \%$, sand $15 \%$, total organic carbon (TOC) $0.89 \%$, total nitrogen (TN) $0.02 \%$, phosphorus $432.1 \mathrm{mg} / \mathrm{kg}$ and $\mathrm{pH} 9.15$.

\section{Biostimulating agents}

Three different biostimulating agents were used in combination with NPK inorganic fertilizer for this study. The composition of NPK inorganic fertilizer (18:8:17
Agroblem SA) was $18 \%$ total nitrogen, $8 \%$ phosphorus pentoxide $\left(\mathrm{P}_{2} \mathrm{O}_{5}\right), 17 \%$ potassium oxide $\left(\mathrm{K}_{2} \mathrm{O}\right), 2 \%$ magnesium oxide $(\mathrm{MgO})$ and $19 \%$ sulphur trioxide $\left(\mathrm{SO}_{3}\right)$. Ivey-surfactant ${ }^{\circledR}$ is a commercial surfactant agent comprised of several patented and preparatory non-ionic surfactant formulations. Biorem is an organic fertilizer utilized as a bulking agent composed of $31.5 \%$ TOC, $3 \%$ nitrogen, $0.06 \%$ phosphorus and $1 \%$ potassium; it is made from cotton fibre seed residue with added nutrients that retain the humidity and bacteria, enhancing hydrocarbon biodegradation. Ethanol is classified as a primary alcohol that contains a hydroxyl group bound to a carbon atom. It has been used as a co-solvent and organic carbon source for several bioremediation projects.

\section{Microcosm assays}

The microcosms were built in $500 \mathrm{ml}$ Erlenmeyer flasks each containing $250 \mathrm{~g}$ of the polluted soil sample. All microcosms were treated with NPK fertilizer and were either or not supplemented with the other biostimulation agents, as detailed in Table 1. A control assay, without addition of any biostimulating product, was included to represent natural attenuation. Microcosms were incubated at room temperature for 14 days according Calvo et al. (2008).

\section{Enumeration of culturable bacteria}

Three replicate samples from each microcosm incubated at room temperature were analysed each week for enumeration of aerobic heterotrophic bacteria and degrading bacteria. $1 \mathrm{~g}$ of soil sample was diluted in $10 \mathrm{ml}$ of sterile saline solution and $0.1 \mathrm{ml}$ volume of each serially diluted soil sample was spread onto plates of $1 / 10$ diluted Tripticase Soy Agar (TSA, Difco), made by preparing 1/10 TSB Difco (Tripticase Soy Broth) and adding $1.5 \%$ agar as previously reported by Sánchez-Peinado et al. (2008). Hydrocarbon-degrading bacteria were counted in $1 \%$ hydrocarbon TSA Difco. Test tubes with $20 \mathrm{ml}$ of TSA

Table 1 Experimental design of the bioremediation treatment using microcosm systems

\begin{tabular}{lllll}
\hline Treatment & $\begin{array}{l}\mathrm{NPK} \text { g/kg } \\
\text { of soil }\end{array}$ & $\begin{array}{l}\text { Ivey } \mu \mathrm{l} / \mathrm{Kg} \\
\text { of soil }\end{array}$ & $\begin{array}{l}\text { Biorem } \\
\mathrm{g} / \mathrm{kg} \text { of soil }\end{array}$ & $\begin{array}{l}\text { Ethanol } \\
\%(\mathrm{w} / \mathrm{w})\end{array}$ \\
\hline $\begin{array}{l}\text { Natural } \\
\text { attenuation }\end{array}$ & - & - & - & - \\
$\begin{array}{l}\text { NPK fertilizer } \\
\text { NPK + Ivey }\end{array}$ & 0.3 & - & - & - \\
$\quad 0.3$ & 52 & - & - \\
$\quad$ surfactant & & & & - \\
NPK + Biorem & 0.3 & - & 80 & - \\
NPK + ethanol & 0.3 & - & - & 2 \\
\hline
\end{tabular}


kept at $45{ }^{\circ} \mathrm{C}$ were added with $0.2 \mathrm{ml}$ of crude oil; they were gently shacked and poured into sterile petri dishes and allowed to solidify. The plates were incubated in triplicate at $28{ }^{\circ} \mathrm{C}$ for $48 \mathrm{~h}$ before the colonies were counted.

\section{Biological activity}

Dehydrogenase activity was determined by the reduction of 2,3,5-triphenylterazolium chloride (TTC) to triphenyl formazan (TPF). A soil sample weighing $20 \mathrm{~g}$ was mixed with $0.2 \mathrm{~g} \mathrm{CaCO}_{3}$. Then, $6 \mathrm{~g}$ of the mixed sample was placed into test tubes and $1 \mathrm{ml}$ of TTC solution (3\%) plus $2.5 \mathrm{ml}$ of distilled water was added. After $24 \mathrm{~h}$ of incubation at $37{ }^{\circ} \mathrm{C}$, the reduced formazan was extracted by adding methanol. The TPF was determined using a spectrophotometer at $485 \mathrm{~nm}$ (Tabatabai 1982).

The production of carbon dioxide $\left(\mathrm{CO}_{2}\right)$ was determined by gas chromatography (Varian Star $3400 \mathrm{cx}$, with a TCD detector). Soil samples for the respiration test were incubated in a closed vessel at $28{ }^{\circ} \mathrm{C}$ (Bremner and Blackmer 1982).

\section{Hydrocarbon analysis}

Total petroleum hydrocarbons (TPH) were determined from the soil samples with a mixture of hexane: acetone 1:1 $(\mathrm{v} / \mathrm{v})$ and determined by gravimetric analyses according to Aguilera Vázquez et al. (2001).

$N$-alkanes and Polycyclic Aromatic Hydrocarbon (PAH) were determined by gas chromatography/mass spectrometry (GC/MS) according USEPA (United States Environmental Protection Agency) (1996, 2000). Analysis of each hydrocarbon fraction was performed from the aforementioned extracted fractions using a Hewlett-Packard 6890 gas chromatography (GC) system equipped with a mass spectrometry (MS) HP-5-MS capillary column (30 $\mathrm{m} \times$ $0.32 \mathrm{~mm}$ I.D.). Helium (1.6 $\mathrm{ml} \mathrm{min}^{-1}$ ) was utilized as the carrier gas. Determinations were performed using the following temperature programme: $40^{\circ} \mathrm{C}$ held for $1 \mathrm{~min}$, followed by heating at a rate of $4{ }^{\circ} \mathrm{C} / \mathrm{min}$ up to $310{ }^{\circ} \mathrm{C}$ and holding the final temperature for $1.5 \mathrm{~min}$. The injector and detector temperatures were $250{ }^{\circ} \mathrm{C}$ and $300{ }^{\circ} \mathrm{C}$, respectively. $\mathrm{N}$-alkanes and Polycyclic Aromatic Hydrocarbon (PAH) were detected using a mass detector 5872 (HewlettPackard) and the library utilized was Wiley 275 respectively.

\section{Statistical analyses}

The mean, variance and standard deviation of the microbiological and chemical parameters were calculated from the values obtained from each of the triplicate samples. Differences between biological: heterotrophic aerobic bacteria, degrading aerobic bacteria, dehydrogenase activity and $\mathrm{CO}_{2}$ production and chemical parameters: TPH, light $n$-alkanes, heavy $n$-alkanes and branched alkanes in the different soil samples were tested by Student's $t$ tests. Cluster analysis comparing biological and chemical variables was used to evaluate the effect of biostimulating agents on the bioremediation process. Single linkage and Pearson correlation have been used to calculate distance or similarity. The statistical significance was evaluated at $P<0.05$. All statistical analyses were carried out using the SPSS (Statistical Package for the Social Sciences) 15.0 software.

\section{Results and discussion}

Biodegradation is nature's way of recycling wastes by breaking down organic matter or inorganic compounds into nutrients that can be used by living organisms (Gan et al. 2009). However, the addition of nutrients such as $\mathrm{N}$ and $\mathrm{P}$ has been reported to enhance bioremediation processes by increasing the microbial biomass (Bento et al. 2005; Sarkar et al. 2005). In this context, supplementation of soil with inorganic fertilizers represents one of the most commonly used approaches in soil bioremediation. Unfortunately, in many cases the application of NPK fertilizers as the sole stimulating agent is not sufficient to totally restore polluted soil (Cunnighan and Philp 2000). This study evaluated the possibility of improving hydrocarbon biodegradation in a clay soil polluted with diesel by the joint application of an NPK fertilizer and other commercial biostimulating products. Three different stimulating agents were tested in combination with NPK fertilizer. Ivey surfactant was included due to the capacity of this product to facilitate the bioavailability of hydrocarbons. Biorem was selected as an organic fertilizer and bulking agent and, finally, ethanol was added as a carbon source that is easily metabolized by soil bacteria.

Microbial activity was evaluated following growth of heterotrophic and degrading microorganisms, dehydrogenase activity and production of $\mathrm{CO}_{2}$ (respiration test). Figures 1 and 2 show the increase in the number of heterotrophic and hydrocarbon-degrading bacteria in the diesel-contaminated microcosms. In these assays, the behaviour of natural attenuation (non-treated microcosms) was compared with the evolution of microbial populations in microcosms amended with NPK fertilizer as the sole stimulating agent and with joint applications of NPK fertilizer and Ivey surfactant, Biorem or ethanol. The results of this study showed that the joint applications increased the number of heterotrophic bacteria in the polluted soil after 14 days of soil incubation. This positive effect was particularly apparent with the joint application of NPK 


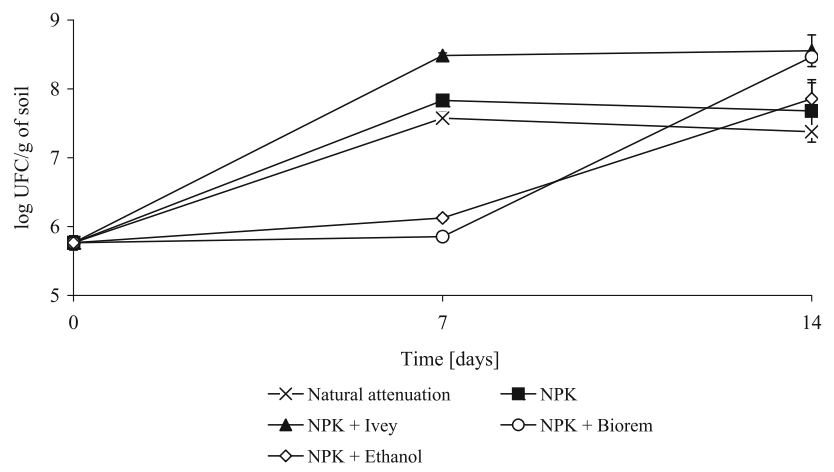

Fig. 1 Number of total heterotrophic bacteria in natural attenuation microcosm (control) and in treated microcosms. Data are means of three replicates

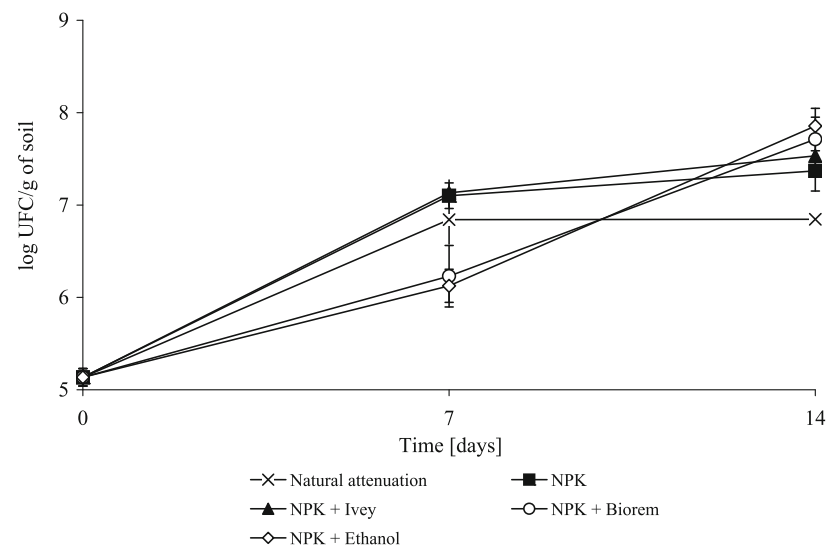

Fig. 2 Number of degrading bacteria in natural attenuation microcosm (control) and in treated microcosms. Data are means of three replicates

fertilizer and Ivey surfactant after 7 days of treatment (Fig. 1), suggesting that the use of Ivey-sol surfactant formulations, as part of a well-designed bioremediation process, will provide a mechanism for desorbing and mobilizing the target contaminants from the surface of the soil to make them more available to indigenous microorganisms.

Regarding hydrocarbon-degrading microorganisms (Fig. 2), application of NPK and NPK + Ivey surfactant rapidly stimulated the growth of hydrocarbon-degrading microorganisms with respect to not only natural attenuation but also Biorem and ethanol addition. At the end of the assays (14 days), all treated microcosms contained a higher number of degrading bacteria than the control microcosm (natural attenuation).

According to Balba et al. (1998) hydrocarbon-degrading microorganisms, the number of total heterotrophic bacteria and hydrocarbon-utilizing bacteria in a contaminated soil can provide useful information on the biological activity in soil. In this sense, Al-Awadhi et al. (1996) reported a strong correlation between microbial counts and hydrocarbon degradation and indicated that such analysis could be a useful tool for following changes concerning microbial activity in hydrocarbon degradation. Under the experimental conditions utilized in the present study, the total microbial counts increased by approximately two orders of magnitude $(P<0.05)$ over the 14 days of incubation. These results suggest that the soil samples contained indigenous microbial populations capable of supporting bioremediation and that none of the nutrients added inhibited microbial growth; furthermore, no toxic effect was observed on the microbial populations.

Microbial activity was evaluated by determining dehydrogenase (DH) activity and the production of $\mathrm{CO}_{2}$. The dehydrogenase activity in soil can be used to monitor activity as an index of the total oxidative activity. In general, the biological oxidation of organic compounds is considered to be a dehydrogenation process catalysed by dehydrogenase enzymes (Paul and Clark 1989). Because the analytical method used in this study to determine the dehydrogenase activity need $24 \mathrm{~h}$ of incubation, the study has considered the first data obtained at the beginning of experiments as dehydrogenase activity at $24 \mathrm{~h}$. These results were compared with the $\mathrm{DH}$ values obtained in a control soil sample without oil pollution and with activity shown at the end of treatment. Thus, to find the effect of the pollutant over the enzymatic activity and estimate the efficiency of the bioremediation treatment, this study established the following indexes:

$\mathrm{ID}_{\mathrm{i} 24 \mathrm{~h} / \mathrm{n}}=\mathrm{DH}$ activity at the beginning of the experiment $\left(D_{\mathrm{i} 24 \mathrm{~h}}\right) / \mathrm{DH}$ activity of non polluted soil $\left(D_{n}\right)$.

$\mathrm{ID}_{14 \mathrm{~d} / \mathrm{n}}=\mathrm{DH}$ activity at the end of the process $\left(D_{14 \mathrm{~d}}\right) /$

DH activity of non polluted soil $\left(D_{n}\right)$.

$\mathrm{ID}_{14 \mathrm{~d} / 24 \mathrm{~h}}=$ DH activity at the end of the process $\left(D_{14 \mathrm{~d}}\right) /$

DH activity at the beginning of experiment $\left(D_{\mathrm{i} 24}\right)$.

The results obtained showed that pollution with diesel produced and important stimulation of dehydrogenase activity. Since the $\mathrm{ID}_{\mathrm{i} 24 \mathrm{~h} / n}$ (Table 2 ) were very similar in all microcosms and always close to 2, further natural attenuation, NPK treatment and NPK + ethanol treatment had analogous behaviour with a diminution in the enzymatic activity with time. In contrast, combined treatment NPK + Ivey surfactant maintains the level of activity (Table 2).

Joint applications of NPK fertilizer and Ivey surfactant and combination of NPK fertilizer and Biorem increased dehydrogenase activity at the end of treatment. However, this positive effect was much more evident (443.58 TPF $\mathrm{g}^{-1}$ ) when the polluted soil samples had been treated with NPK fertilizer plus Biorem (Table 2).

In contrast, in the control microcosms and when the soil microcosms had been treated with NPK fertilizer alone and NPK fertilizer and ethanol, a decrease in dehydrogenase 
Table 2 Microbial activity estimated by dehydrogenase and production of $\mathrm{CO}_{2}$ in diesel polluted soil microcosms under the experimental condition studies

\begin{tabular}{|c|c|c|c|c|c|}
\hline \multirow[t]{2}{*}{ Treatment } & \multicolumn{3}{|c|}{ Dehydrogenase } & \multicolumn{2}{|l|}{$\% \mathrm{CO}_{2} 24 \mathrm{~h}$} \\
\hline & $\mathrm{ID}_{\mathrm{i} 24 \mathrm{~h} / \mathrm{n}}$ & $\mathrm{ID}_{14 \mathrm{~d} / \mathrm{n}}$ & $\mathrm{ID}_{14 \mathrm{~d} / 24 \mathrm{~h}}$ & $T_{0 \text { days }}$ & $T_{14 \text { days }}$ \\
\hline Natural attenuation & 2.46 & 0.40 & 0.16 & $0.05 \pm 0.008$ & $0.03 \pm 0.000$ \\
\hline NPK & 2.46 & 0.44 & 0.18 & $0.05 \pm 0.008$ & $0.18 \pm 0.034^{\mathrm{a}}$ \\
\hline NPK + Ivey & 1.89 & 2.48 & 1.31 & $0.32 \pm 0.016$ & $0.07 \pm 0.010^{\mathrm{a}}$ \\
\hline NPK + Biorem & 2.46 & 14.84 & 6.02 & $0.05 \pm 0.008$ & $0.99 \pm 0.185^{\mathrm{a}}$ \\
\hline NPK + ethanol & 2.46 & 0.39 & 0.16 & $0.05 \pm 0.008$ & $1.83 \pm 0.186^{\mathrm{a}}$ \\
\hline$P^{a}$ & $*$ & $*$ & & $*$ & $*$ \\
\hline
\end{tabular}

$P^{a}$ from one-way ANOVA, $* * *, * *, * 0.001,0.01,0.5$, respectively

Labels: (a) indicates statistically significant difference between $t=0$ days and $T=14$ days, using Student's $t$ test; $P<0.05$

activity was detected after 14 days of incubation (Table 2). Obviously, these results do not correlate with the high number of bacteria counted in these microcosms. However, Balba et al. (1998) indicated that dehydrogenase activity is correlated with the total metabolic activity of soil microorganisms, and this can be modified by different biotic and abiotic factors. Thus, it has been reported that factors such as nitrate, nitrite and ferric ion concentrations or modifications in the biodiversity of the microbial communities can affect the dehydrogenase activity in a soil (Sarkar et al. 2005; Margesin et al. 2000). More experiments are being conducted by us in the laboratory of Environmental Microbiology (University of Granada, Spain) to address this issue.

Soil respiration (production of $\mathrm{CO}_{2}$ ) can be considered as a parameter of the total biological activity and results from the degradation of organic matter. According to this parameter, the microcosms amended with NPK fertilizer and ethanol produced the highest levels of $\mathrm{CO}_{2}$. It seems that ethanol enhances bacterial metabolism, suggesting that its addition at low concentrations would stimulate indigenous microorganisms tolerant to diesel pollution. In the

Table 3 Variation in water content of soil microcosms during bioremediation treatment

\begin{tabular}{llll}
\hline Treatment & \multicolumn{2}{l}{$\begin{array}{l}\text { o of humidity } \\
\text { lost }\end{array}$} & \multicolumn{2}{l}{$\%$ of moisture } \\
\cline { 3 - 4 } & & $t_{0 \text { days }}$ & $t_{14 \text { days }}$ \\
\hline $\begin{array}{l}\text { Natural } \\
\text { attenuation }\end{array}$ & 9.05 & $24.75 \pm 0.5$ & $22.51 \pm 2.3$ \\
NPK & 22.76 & $27.24 \pm 1.2$ & $21.04 \pm 2.2$ \\
NPK + Ivey & 3.84 & $24.71 \pm 0.5$ & $23.76 \pm 0.4$ \\
NPK + Biorem & -0.57 & $27.97 \pm 0.3$ & $28.13 \pm 1.4$ \\
NPK + ethanol & 29.61 & $26.78 \pm 0.4$ & $18.85 \pm 0.5^{\text {a }}$ \\
& $P^{a}$ & $*$ & $*$ \\
\end{tabular}

$P^{a}$ from one-way ANOVA, ***, **, * $<0.001,0.01,0.5$, respectively. Labels: (a) indicates statistically significant difference between $t=0$ days and $T=14$ days, using Student's $t$ test; $P<0.05$ same way, Biorem treatment also enhanced $\mathrm{CO}_{2}$ production, showing that in soil with a clay texture the application of a bulking agent would be an efficient tool for soil remediation.

Moisture is also an important variable in soil habitats (Scheutz and Kjeldsen 2004). In general, microbial growth decreases the soil water content as a consequence of microbial metabolism, and previous results obtained in the laboratory of Environmental Microbiology (University of Granada, Spain) regarding the bioremediation of hydrocarbon-polluted soils also demonstrated the fact that moisture is one of the most important parameters to be taken into account, with values higher than $13 \%$ being necessary for optimal microbial activity and hydrocarbon degradation (Calvo et al. 2009). Thus, the application of products that maintain humidity could be useful (particularly in arid and semiarid climates) for enhancing soil microbial activity and also for increasing hydrocarbon degradation. The data obtained have shown that the joint application of NPK fertilizer and Biorem or Ivey ${ }^{\circledR}$ surfactant reduced the amount of water lost in the microcosms, suggesting that these treatments ensure adequate conditions for bioremediation (Table 3).

Chromatographic analysis was used to estimate the degradation of TPH, light $n$-alkanes (C10-C20), heavy $n$-alkanes (C21-C40) and branched alkanes. A degradation index (Id) was also considered using the natural attenuation microcosm as a reference and was calculated by the following expression: [\% of degradation in each treatment $/ \%$ of degradation in natural attenuation treatment]. The results showed that the removal efficacy varied depending on the type of hydrocarbon (Table 4) and that treatment with NPK plus Ivey ${ }^{\circledR}$ surfactant was the most efficient in terms of the removal of TPH $(\mathrm{Id}=1.4)$ and light $n$-alkanes $(\mathrm{Id}=1.3)$. There was also a high rate of the degradation of heavy $n$-alkanes and branched alkanes in microcosms supplemented with NPK fertilizer plus ethanol, with Id values of 1.6 and 1.5, respectively (Fig. 3). These results suggest that 
Table 4 Index of biodegradation (Id) and percentage of hydrocarbon removal in soil microcosms treated with NPK fertilizer, NPK fertilizer + Ivey surfactant, NPK fertilizer + Biorem, NPK fertilizer + ethanol

\begin{tabular}{|c|c|c|c|c|c|c|c|c|}
\hline \multirow[t]{2}{*}{ Treatment } & \multicolumn{2}{|l|}{ Alkanes $<20$} & \multicolumn{2}{|l|}{ Alkanes $>20$} & \multicolumn{2}{|c|}{ Branched alkanes } & \multicolumn{2}{|l|}{ TPH } \\
\hline & $\%$ & Id & $\%$ & Id & $\%$ & Id & $\%$ & Id \\
\hline Natural attenuation & $64.0 \pm 1.29$ & 1.0 & $57.1 \pm 2.59$ & 1.0 & $63.8 \pm 2.05$ & 1.0 & $41.4 \pm 9.08$ & 1.0 \\
\hline NPK & $36.5 \pm 1.09$ & 0.6 & $66.5 \pm 0.57$ & 1.2 & $66.5 \pm 0.57$ & 1.1 & $37.8 \pm 1.07$ & 0.9 \\
\hline NPK + Ivey & $84.7 \pm 0.73$ & 1.3 & $71.1 \pm 1.33$ & 1.3 & $71.1 \pm 1.33$ & 1.1 & $57.4 \pm 1.96$ & 1.4 \\
\hline NPK + Biorem & $42.7 \pm 0.07$ & 0.7 & $64.1 \pm 0.04$ & 1.1 & $64.1 \pm 0.04$ & 1.0 & $34.2 \pm 17.79$ & 0.8 \\
\hline $\mathrm{NPK}+$ ethanol & $41.6 \pm 0.22$ & 0.7 & $92.6 \pm 0.03$ & 1.6 & $92.6 \pm 0.03$ & 1.5 & $42.0 \pm 0.22$ & 1.0 \\
\hline$P^{a}$ & $* * *$ & $* * *$ & $* * *$ & $* * *$ & & & & \\
\hline
\end{tabular}

$P^{a}$ from one-way ANOVA, ***, **, * $<0.001,0.01,0.5$, respectively

Fig. 3 Index of degradation of light and heavy $n$-alkanes, branched alkanes and TPH in diesel-polluted soil microcosms after application of biostimulating treatments

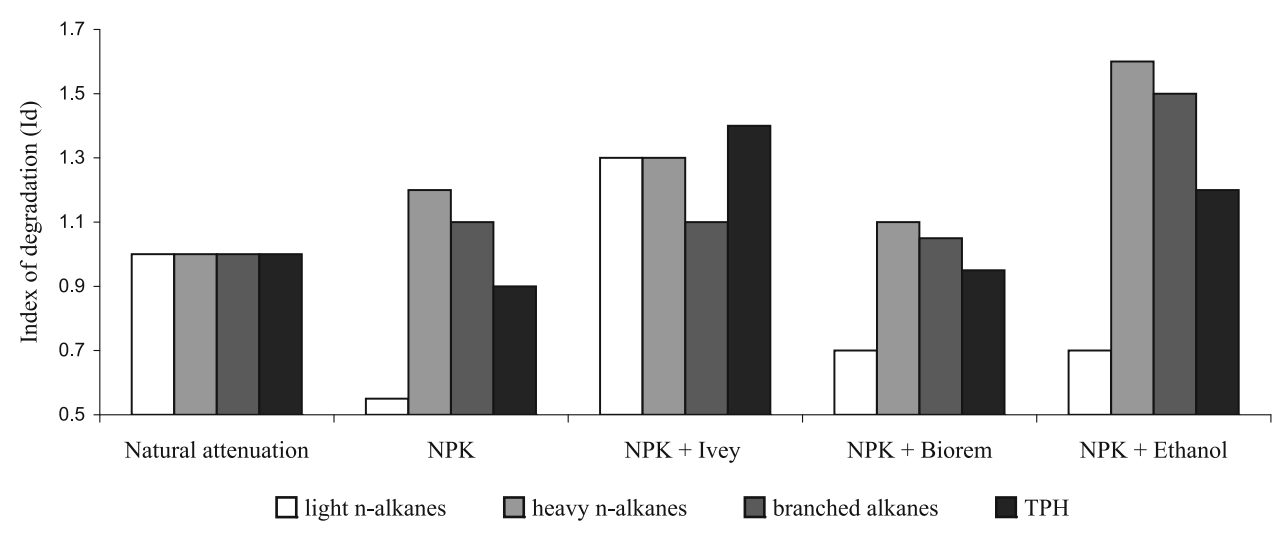

combined treatments would be a suitable choice for the bioremediation of hydrocarbon-polluted clay soil. Figure 4 shows the reduction in the hydrocarbon chromatogram areas detected in soil samples from the NPK + Ivey surfactant microcosm at the end of treatment and illustrates the usefulness of this combined biostimulating treatment.

Normally, hydrophobic organic chemicals (HOC) exhibit limited bioavailability to microorganisms as the contaminants tend to partition onto the soil matrix. This partitioning can account for as much as $95 \%$ or more of the total contaminant mass. Thus, this limits the concentration of HOC, such as hydrocarbon compounds, that are available to the microbial population. Hence, these compounds can persist in the soil matrix for long periods of time. The use of Ivey surfactant formulations, as part of a welldesigned bioremediation process, will provide a mechanism for desorbing and mobilizing the target contaminants from the surface of the soil to make them more available to microbial populations. Many authors have reported that the rate of hydrocarbon degradation can be significantly affected by the rate of desorption of these compounds from soil particles (Singh et al. 2007; Haritash and Kaushisk 2009). For this reason, the application of surfactants has been considered as a useful tool in bioremediation
Fig. 4 Chromatograms of soil samples obtained after 14 days of treatment from each of the soil microcosms studied 
processes to accelerate the microbial biodegradation capacity. Figure 3 shows that the addition of inorganic fertilizer plus Ivey-sol (C) generally enhanced hydrocarbon biodegradation. Moreover, the numbers of heterotrophic and hydrocarbon-degrading bacteria were significantly enhanced $(P<0.05)$. Consequently, as previously reported by other authors, the results of this study confirm that the application of surfactants as stimulating agents improves bioremediation, at least under the present experimental conditions.

Biorem is a bulking agent that increases the porosity and oxygen diffusion in soils. The addition of bulking agents such as Biorem tends to have a priming effect on microbial populations and they might also play a role in reducing soil bulk density, as well as serving as an additional organic material during bioremediation (Vasudevan and Rajaram 2001)]. The results showed that this treatment led to a remarkable stimulation of microbial activity, with a high capacity for maintaining moisture $(28.13 \%)$ and an average rate of biodegradation $(51.27 \%)$. Similar data were reported by Rhykerd et al. (1999), who demonstrated that bulked soils showed a more rapid reduction in TPH (82\% in 12 weeks) compared with the non-bulked control (33\% in 12 weeks). They concluded that bulking agents and tillage enhanced bioremediation processes, possibly by reducing the size of oil-saturated aggregates, and thereby exposing more of the oil to microbial activity.

Treatments with NPK fertilizer plus ethanol produced better results than with NPK fertilizer alone $(P<0.05)$ (Table 4). Lovanh et al. (2002) studied the effect of ethanol on BTEX biodegradation kinetics in aerobic continuous culture experiments to determine how ethanol affects benzene, toluene, ethylbenzene and xylene (BTEX) biodegradation kinetics. In all cases, the presence of ethanol increased microbial biomass, which is conducive to faster degradation rates. Under carbon-limiting conditions $(1 \mathrm{mg} / \mathrm{L}$ influent benzene), the data and model simulations showed an increase in benzene removal efficiency when ethanol was fed at low concentrations because its positive effect on cell growth. High ethanol concentrations, however, had a negative effect, causing oxygen limitation.

Further, it has also been reported that addition of ethanol can stimulate metabolism for denitrifying bacteria which become enriched after the application of this compound, and consequently resulting in anaerobic hydrocarbon biodegradation (Chen et al. 2008). The results seem indicate that the low ethanol concentration used in these experiments could have enhanced the metabolic activity of some microbial groups including anaerobic microorganisms such as denitrifying or sulphate-reducing bacteria. However, this observation must be considered with care since soil is a very complex habitat and its microbial activity can be affected by many different biotic and abiotic parameters.

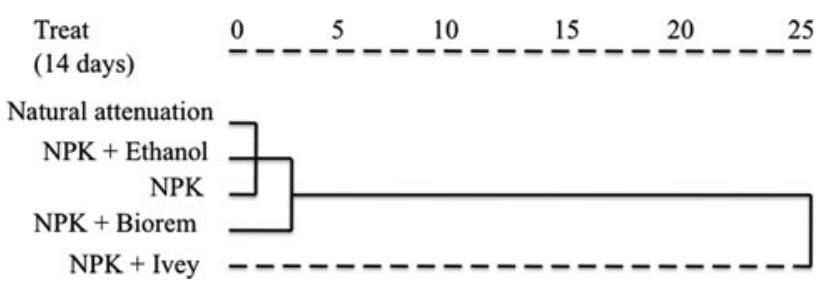

Fig. 5 Dendrogram using single linkage and Pearson correlation

Finally, the cluster analysis comparing biological and chemical variables was used to evaluate the effect of biostimulating agents on the bioremediation process. Figure 5 shows three groups of similarity, one of them including natural attenuation, ethanol and NPK with less than $2 \%$ dissimilarity. The Biorem treatment also showed high similarity with the aforementioned group (5\% dissimilarity). Finally, the NPK + Ivey surfactant treatment showed the highest percentage of dissimilarity (25\%), suggesting that the application of a surfactant introduces changes to the soil system and leads to important modifications in microbial behaviour, which could explain the efficiency of this treatment in the remediation of hydrocarbon-polluted clay soil.

\section{Conclusions}

Studies of biodegradation using soil microcosms can be used to assess the biodegradation potential of hydrocarbons present in a contaminated soil to determine the most appropriate bioremediation strategy for large-scale applications. Our studies showed that the application of nutrients and biostimulation agents increased hydrocarbon biodegradation, although the efficiency of the treatments was affected by the type of stimulating agent applied and obviously by the type of hydrocarbon. The results showed that the use of inorganic fertilizers, such as NPK, plays an important role in the bioremediation of oil-contaminated soil, particularly in soils in which the microbiological population is adapted to pollutants. However, the efficiency of the inorganic fertilizer used in the present study was clearly enhanced when applied together with the Ivey surfactant or with ethanol, suggesting that, via different mechanisms, these stimulating agents can increase the effectiveness of bioremediation within a short period of time. Obviously, our study was performed in clay soil microcosms artificially contaminated with diesel. In this context, more experiments are needed to determine the most favourable procedure that could be applied for the bioremediation of a natural environment.

Acknowledgments This research was supported by the Ministerio de Medio Ambiente (MMA, A4872007/20-01.1). 


\section{References}

Aguilera Vázquez L, Soto-Cruz NO, Saucedo-Castañeda G, Gutiérrez-Rojas M (2001) A model system for composting hydrocarbon contaminated soil by using water activity and porosity as response variable. Chem Eng J 88:197-202

Al-Awadhi N, Al-Daher R, El-Nawawy A, Balba MT (1996) Bioremediation of oil-contaminated soil in Kuwait I. Landfarming to remediate oil-contaminated soil. J Soil Contam 5:243-260

Balba MT, Al-Awadhi N, Al-Daher R (1998) Bioremediation of oil-contaminated soil: microbiological methods for feasibility assessment and field evaluation. J Microbiol Methods 32:155164

Banat IM, Makkar RS, Cameotra SS (2000) Potential commercial applications of microbial surfactants. Appl Microbiol Biotechnol 53:495-508

Bento FM, Camargo F, Okeke B, Frankenberger W (2005) Comparative bioremediation of soils contaminated with diesel oil by natural attenuation, biostimulation and bioaugmentation. Bioresour Technol 96:1049-1055

Bremner MJ, Blackmer AM (1982) Composition of soil atmospheres. In: Page AL, Miller RH, Keeney DR (eds) Methods of soil analysis: Part 2. Chemical and Microbiological Properties, American Society of Agronomy, Soil Science Society of America, Madison, Wisconsin, USA, pp 903-943

Calvo C, Silva-Castro GA, Perucha P, Laguna J, Uad I, GonzálezLópez J (2008) When can surfactants enhance hydrocarbon biodegradation in oil biotreatments? In: Kungolos AG, Brebbia CA, Zamorano M (eds) Environmental toxicology II. WIT press, Southampton, Boston

Calvo C, Manzanera M, Silva-Castro GA, Uad I, Gonzalez-Lopez J (2009) Application of bioemulsifiers in soil oil bioremediation processes. Future prospects. Sci Total Environ 407:3634-3640

Chen YD, Barker JF, Gui L (2008) A strategy for aromatic hydrocarbon bioremediation under anaerobic conditions and the impacts of ethanol: A microcosm study. J Contam Hydrol 96:17-31

Cunnighan CJ, Philp JC (2000) Comparison of biostimulation in exsitu treatment of diesel contaminated soil. Land Contam Reclam $8: 261-269$

Franzetti A, Di Gennaro P, Bestetti G, Lasagni M, Pitea D, Collina E (2008) Selection of surfactants for enhancing diesel hydrocarbons-contaminated media bioremediation. J Hazard Mater 152:1309-1316

Gan S, Lau EV, Ng NK (2009) Remediation of soil contaminated with polycyclic aromatic hydrocarbons (PAHs). J Hazard Mater 172:532-549

Haritash AK, Kaushisk CP (2009) Biodegradation aspect of polycyclic aromatic hydrocarbons (PAHs): a review. J Hazard Mater 169:1-15

Kanaly RA, Harayama S (2000) Biodegradation of high-molecularweight polycyclic aromatic hydrocarbons by bacteria. J Bacteriol 182:2059-2067

Lovanh N, Hunt CS, Alvarez PJJ (2002) Effect of ethanol on BTEX biodegradation kinetics: aerobic continuous culture experiments. Water Res 36:3739-3746
Margesin R, Walder G, Schinner F (2000) The impact of hydrocarbon remediation (diesel oil and polycyclic aromatic hydrocarbons) on enzyme activity and microbial properties of soil. Acta Biotechnol 20:313-333

Mulligan CN, Yong RN, Gibbs BF (2001) Surfactant-enhanced remediation of contaminated soil: a review. Eng Geol 60:371380

Nikolopoulou N, Kalogerakis N (2008) Enhanced bioremediation of crude oil utilizing lipophilic fertilizers combined with biosurfactants and molasses. Mar Pollut Bull 56:1855-1861

Olsen SR, Sommers LE (1982) Phosphorus. In: Page AL, Miller RH, Keeney DR (eds) Methods of Soil Analysis: Part 2. Chemical and Microbiological Properties, American Society of Agronomy, Soil Science Society of America, Madison, Wisconsin USA, pp 699-708

Paul EA, Clark FE (1989) Soil microbiology and biochemistry. Academic Press, New York

Rhykerd RL, Crews B, Mclnnes KJ, Weaver RW (1999) Impact of bulking agents, forced aeration and tillage on remediation of oilcontaminated soil. Bioresour Technol 67:279-285

Ron EZ, Rosenberg E (2002) Biosurfactants and oil bioremediation. Curr Opin Biotechnol 13:249-252

Sabaté J, Viñas M, Solanas AM (2004) Laboratory-scale bioremediation experiments on hydrocarbon-contaminated soils. Int Biodeterior Biodegrad 54:19-25

Sánchez-Peinado M, González-López J, Rodelas B, Galera V, Pozo C, Martínez Toledo MV (2008) Effect of linear alkyl benzene sulfonates on the growth of aerobic heterotrophic cultivable bacteria isolate from an agricultural soil. Ecotoxicology 17:459_ 557

Sarkar D, Ferguson M, Datta R, Birnbaum S (2005) Bioremediation of petroleum hydrocarbons in contaminated soil: comparison, and monitored natural attenuation. Environ Pollut 136:187-195

Scheutz C, Kjeldsen P (2004) Environmental factors influencing attenuation of methane and hydrochlorofluorocarbons in landfill cover soils. J Environ Qual 33:72-79

Singh A, Van Hamme DJ, Ward PO (2007) Surfactants in microbiology and biotechnology: Part 2: Application aspects. Biotechnol Adv 25:99-121

Soil Conservation Service, Soil Taxonomy (1975) A Basic System of Soil Classification for Making and Interpreting Soil Surveys, US Department of Agriculture, Washington, DC

Tabatabai MA (1982) Soil Enzymes. In: Page AL, Miller RH, Keeney DR (eds) Methods of Soil Analysis: Part 2. Chemical and Microbiological Properties, American Society of Agronomy, Soil Science Society of America, Madison, Wisconsin USA, pp 903-943

USEPA (United States Environmental Protection Agency) (1996) Hazardous Waste-test Methods, 8015: Nonhalogenated Organics by GAS Chromatography

USEPA (United States Environmental Protection Agency) (2000) Determination of polynuclear aromatic hydrocarbons in industrial and municipal wastewater EPA-600/4-00-025. Environmental monitoring. System Laboratory, Cincinnati

Vasudevan N, Rajaram P (2001) Bioremediation of oil sludgecontaminated soil. Environ Int 26:409-411 